\title{
Slaviša Đorđević*
}

\section{ZNAČAJ PREVAZILAŽENJA RAZLIKA U KULTURI U AKVIZICIONIM PROCESIMA}

Sažetak: Uprkos visokim stopama neuspeha, različiti oblici prestrukturiranja korporativnih privrednih društava još uvek predstavljaju jedan od često korišćenih načina za realizovanje određenih strateških ciljeva, kao i identifikovanih $i$ anticipiranih sinergetskih efekata. U ovom članku pokušali smo da ukažemo na značaj koji u akvizicionim procesima može imati kulturna integracija dva entiteta ili pak razvoj nove kulture na konačan uspeh preduzetih transakcija.

Ključne reči: neuspešni merdžeri, postakviziciona integracija, razlike u kulturi.

\section{THE SIGNIFICANCE OF CULTURAL DIFFERENCES OVERCOME IN ACQUISITION PROCESSES}

\begin{abstract}
Besides the high merger failure rate, different types of corporation restructuring are still one of the most popular ways to realize particular strategic goals, as well as the identified and anticipated synergy effects. In this article we tried to point at the significance that might have cultural integration on the final derived transactions of two entities or new culture development in acquisition processes.
\end{abstract}

Keywords: merger failure, post-acquisition integration, cultural difference.

\section{UVOD}

Različiti oblici prestrukturiranja korporativnih privrednih društava u zemljama sa razvijenom tržišnom privredom, a naročito u SAD, bilo kroz procese kombinovanja (spajanje, pripajanje ili preuzimanje) ili pak procese dezinvestiranja, predstavljaju fenomene koji već više od jednog stoleća zaokupljaju pažnju teoretičara i praktičara širom sveta. Intenzitet interesovanja određen je, pre svega, brojem ostvarenih (ne)uspešnih procesa kombinovanja ili dezinvestiranja koji se realizuju u određenim vremenskim periodima.

Periodi intenzivnih aktivnosti na realizovanju različitih oblika prestrukturiranja korporativnih privrednih društava, koji se nazivaju merdžer talasi, ukazuju na to da su se u određenim vremenskim periodima trošile ogromne sume novca na transakcije čiji su efekti, najblaže rečeno, daleko ispod očekivanih. Poslednjih dvadeset godina, u petom merdžer talasu, stvarani su tzv. prekogranični megamerdžeri, odnosno realizovani su akvizicioni procesi između dva giganta u određenim industrijskim granama.

S obzirom na različito definisanje samog pojma „neuspešna poslovna kombinacija“, kao i na veliki broj uzroka koji su uticali da neka transakcija, a posebno one iz poslednjeg merdžer talasa, ponese epitet neuspešne, u nastavku ćemo pokušati da: obrazložimo neke uzroke koji su uticali na to da akvizicije ne ostvare anticipirane i identifikovane sinergetske efekte, ukažemo na značaj prevazilaženja razlika u kulturi između učesnika u akvizicionim procesima kako bi se poboljšali

\footnotetext{
* Dr Slaviša Đorđević, profesor strukovnih studija, Visoka poslovna škola strukovnih studija, Vladimira Perića Valtera 4, Novi Sad,drsdj63@gmail.com.
} 
efekti poslovnih kombinacija i, najzad, ilustrujemo naša izlaganja pozitivnim i negativnim primerima uticaja razlika u kulturi na uspeh celokupnog akvizicionog procesa.

\section{NEUSPEŠNE POSLOVNE KOMBINACIJE}

Već kod definisanja pojma neuspešne poslovne kombinacije, nailazimo na različite stavove pojedinih teoretičara i praktičara koji su se ozbiljnije bavili ovim fenomenom. Naime, prema jednom mišljenju akvizicija se može smatrati uspešnom ako u izvesnom vremenskom periodu (nekoliko godina) ciljna kompanija ostane u rukama sticateljske kompanije (Niyati, 2008: 1). Empirijske studije koje su u definisanju (ne)uspeha koristile ovakav pristup, utvrdile su da je stopa neuspešnih poslovnih kombinacija između 50 i 75\%. Druge empirijske studije pak ukazuju na činjenicu da su zaključci o uspešnosti procesa kombinovanja korporativnih preduzeća različiti u zavisnosti od načina definisanja (ne)uspeha. Ukoliko se termin „,neuspeh“ upotrebljava u ekstremnom smislu, kao što je prestanak rada entiteta koji je rezultat procesa kombinovanja, odnosno njihova prodaja ili likvidacija, onda je stopa neuspeha ovih procesa relativno niska. Ako pak neuspeh predstavlja nemogućnost da entitet ostvari finansijske ciljeve menadžmenta, onda je stopa neuspeha visoka (United Nations Conference on Trade and Development, 2000: 139). Osim toga, rezultati istraživanja determinisani su periodima koji su uzeti u razmatranje, vrstama preduzetih akvizicija (prijateljske ili neprijateljske), kao i motivima koji su bili dominantni pri odlučivanju o ulaženju u ove rizične poduhvate. Takođe, na (ne)uspeh akvizicionog procesa uticalo je i iskustvo koje su sticateljske kompanije imale u prethodnim periodima, tako da su kompanije ,,... sa značajnim iskustvom u poslovima ove vrste bolje u selektovanju adekvatne ciljne korporacije i upravljanju procesom postakvizicione integracije, od akvizicionih kompanija koje imaju manje ili nimalo iskustva.“ (Meschi, Metais, 2008: 4). Visoke stope neuspeha posledica su činjenice da su akvizicioni procesi izuzetno složeni, kompleksni, komplikovani i dugotrajni, tako da eventualni propusti u bilo kojoj od faza akvizicionog procesa (Đorđević, 2007: 38-58). mogu dovesti do toga da se nameravana poslovna kombinacija ili uopšte ne realizuje, ili da nije u stanju da realizuje identifikovane i anticipirane sinergetske efekte.

U napred navedenim istraživačkim studijama, kao i u mnogim udžbenicima i stručnim člancima, pridaje se različit značaj pojedinim uzrocima koji su onemogućili uspeh akvizicionih procesa. Primera radi, Robert F. Bruner u svojoj knjizi slikovitog naziva „Deals from Hell“ ukazuje na sledeće uzroke neuspeha akvizicionih procesa (Bruner, 2005: 8-9).

- Prvi uzrok tiče se strategije. Kod najuspešnijih poslovnih kombinacija kupac stiče ciljnu korporaciju koja posluje u povezanim oblastima, odnosno granama delatnosti. Međutim, kod neuspešnih poslovnih kombinacija ciljne korporacije se nalaze u granama delatnosti koje su različite. Bolje poznavanje povezanih grana delatnosti imaće za posledicu manje iznenađenja i više šansi za uspeh.

- Izbor pogodne ciljne korporacije značajno utiče na uspeh poslovne kombinacije. Kod neuspešnih transakcija, sticateljska korporacija poseže za akvizicijama zbog svojih slabosti. U takvim situacijama ciljna korporacija ima značajno jaču poziciju, pa nije teško zaključiti da sticateljska korporacija pokušava da akvizicijom prevaziđe određene probleme.

- Neuspešne transakcije su najčešće u nestabilnim tržišnim uslovima. Nedavna istraživanja sugerišu da su mnoge transakcije motivisane strategijskim turbulencijama u određenim granama. Najuspešnije transakcije su vezane za stabilne tržišne uslove.

- Najzad, uspeh zavisi i od načina plaćanja transakcije. Uspešnije transakcije su povezane sa plaćanjem gotovim novcem, dok su neuspešne transakcije obično finansirane izdavanjem, odnosno razmenom hartija od vrednosti (akcijama).

Sa druge strane, rezultati istraživačke studije računovodstvene i konsultantske firme Coopers \& Lybrand, koja je sada sastavni deo PricewaterhouseCoopers, kojom su bile obuhvaćene najveće 
akvizicije u Velikoj Britaniji sa minimalnom vrednošću od 100 miliona funti, a realizovane su u kasnim osamdesetim i ranim devedesetim godinama XX veka, i koji su uticali na naše opredeljenje da rad posvetimo uticaju prevazilaženja razlika u kulturi u akvizicionim procesima, navode kao osnovne uzroke neuspeha akvizicionih procesa sledeće:

- otpor menadžmenta ciljne korporacije i razlike u kulturi $(85 \%)$;

- nepostojanje plana postakvizicione integracije (80\%);

- nedovoljno poznavanje grane delatnosti ili ciljne korporacije (45\%);

- loše upravljanje ciljnom korporacijom (45\%) i

- nedostatak iskustva u realizovanju poslovnih kombinacija (30\%) (Sudarsanam, 2003: 231).

Iako rezultati istraživačke studije posebno ističu uticaj nedostatka programa postakvizicione integracije i razlika u kulturi na uspeh preduzetih transakcija, smatramo da pravazilaženje navedenih razlika treba da bude sastavni deo ovog programa. S tim u vezi, pre nego što ukažemo na pozitivne i negativne primere vezane za uticaj razlika u kulturi u akvizicionim procesima, pokušaćemo da u najkraćem obrazložimo postupke koji mogu doprineti uspešnom postakvizicionom integrisanju uključenih entiteta $i$, na posredan način, prevazilaženju razlika $u$ kulturi.

\section{PROGRAM POSTAKVIZICIONE INTEGRACIJE}

Jedan od najčešćih problema koji se javljaju u realizaciji nekog od oblika poslovnih kombinacija je, svakako, problem tzv. postakvizicione integracije. Ovaj problem je znatno složeniji kada su u pitanju prekogranične akvizicije, mada se, sa manjim intenzitetom, ispoljava i u akvizicijama korporacija iz iste zemlje, a posledica je različitosti u razvijenosti pojedinih država ili oblasti u okviru iste države, kao i različitosti u ponašanju i kulturi menadžmenta i zaposlenih u sticateljskoj i ciljnoj korporaciji. Prema jednom shvatanju, veliki broj neuspešnih akvizicionih procesa nije posledica činjenice da je ,... osnovna strategija koja je podstakla transakciju bila loša, već zato što je sprovođenje procesa integracije bilo brzopleto, aljkavo i neefikasno." (Shuler, 2010: 2).

Proces planiranja postakvizicione integracije potrebno je započeti u poslednjim fazama procesa akvizicije, paralelno sa postizanjem konsenzusa o bitnim elementima akvizicionog sporazuma. Iako bi se na prvi pogled moglo zaključiti da je najvažniji deo posla završen potpisivanjem akvizicionog sporazuma, dosadašnje iskustvo potvrđuje da je detaljan program postakvizicione integracije $\mathrm{i}$ brzina njegove implementacije jedan od važnijih, ako ne i najvažniji uzrok (ne)uspeha procesa akvizicije.

Programi postakvizicione strategije razlikuju se u zavisnosti od toga da li sticateljska korporacija želi da ostvari punu asimilaciju ciljne korporacije (njeno potpuno prilagođavanje stilu poslovanja sticateljske korporacije), ili dozvoljava ciljnoj korporaciji da u potpunosti zadrži postojeći stil poslovanja, ili pak da ga neznatno promeni na način koji joj omogućava da zadrži sopstveni identitet koji se razlikuje od identiteta sticateljske korporacije.

\section{UTICAJ RAZLIKA U KULTURI NA USPEH PROCESA AKVIZICIJE}

Bez obzira na to kako je strukturiran program postakvizicione integracije on bi morao da obezbedi i „kulturnu integraciju“, odnosno afirmaciju nove filozofije u ciljnoj korporaciji, kao i efikasnu integraciju načina mišljenja i ponašanja svih zaposlenih.

Jedna od najčešće isticanih korporacija koja je uspevala da efikasno integriše ciljne korporacije iz različitih zemalja je svakako Elektrolux, poznata švedska korporacija koja se bavi proizvodnjom aparata za domaćinstvo. Njen prilaz rešavanju problema koji su posledica različitosti u kulturi ,... bio je da treba prihvatiti i čak zaštititi kulturni identitet ciljne kompanije. Praktikovali su zadržavanje izvršnih direktora ciljne korporacije, nedvosmisleno im ustupajući kontrolu nad 
poslovanjem, realizovanje dogovorenih ciljeva i, u vezi sa tim, njihovu dobrovoljnu saradnju i integrisanje sa ostatkom grupe." (Sudarsanam, 2003: 532).

U 1985. godini korporacija Elektrolux je uspešno realizovala akviziciju korporacije Zanussi, italijanskog proizvođača aparata za domaćinstvo. Najvažniji koraci koje je preduzela kompanija Elektrolux i koji su omogućili efikasno integrisanje i profitabilno poslovanje kompanije Zanussi ogledali su se, između ostalog, u sledećem: brza implementacija integracionog plana; imenovanje novog tima menadžera, koji je uveo novu kulturu zasnovanu na švedskom radnom moralu; obezbeđeni su uravnoteženi uslovi kreditiranja za sve potrošače, kao i povoljniji uslovi za finansijere i dobavljače; sa ciljevima transakcije upoznat je sindikat Zanussi-ja i obezbeđena je njegova podrška; realizovane su uzajamne posete top-menadžera Elektrolux-a i Zanussi-ja; menadžmentu Zanussi-ja data je značajna autonomija, pa su važnije funkcije ostale u Italiji, nasuprot pesimističkim očekivanjima menadžmenta i zaposlenih u ciljnoj korporaciji da će dominantnu ulogu u upravljanju italijanskom kompanijom imati menadžment Elektrolux-a; iniciran je transfer strateških resursa u oba pravca; izvršena je brza i efikasna kontrola u računovodstvu i finansijama, što je sve imalo za posledicu stvaranje pozitivne atmosfere koja je doprinela uzajamnom razumevanju između sticateljske i ciljne korporacije (Sudarsanam, 1995: 276).

Sa druge strane, najčešće citirana poslovna kombinacija za čiji neuspeh su „okrivljene“ razlike u kulturi jeste kombinacija Daimler-Benz-a i Chrysler-a, poslovna kombinacija iz 1998. godine. Učesnici ove transakcije vredne $\$ 36$ milijardi bili su poznati proizvođači automobila iz SAD i Nemačke.

Na jednoj strani je bila kompanija Chrysler, sredinom 90-tih godina XX veka najprofitabilniji svetski proizvođač automobila. Prihodi od prodaje lakih kamiona, kombi vozila i velikih automobila bili su izuzetno visoki. Chrysler je preuzeo rizik u proizvodnji vozila koja su bila odraz američkog pionirskog duha i kod kojih je uvoz dominirao na tržištu, kao što su Dodge Ram, džip Grand Cherokee i limuzine LH Sedan serije. Sa ovim vozilima Chrysler je ostvario uspeh i njegovo učešće na tržištu SAD je poraslo na $23 \%$ u 1997. godini. Porast prihoda i tržišnog učešća imali su za posledicu smanjenje udela troškova razvoja proizvoda na $2,8 \%$ ukupnih prihoda. Na drugoj strani je bila kompanija Daimler-Benz, čuveni proizvođač mercedes luksuznih vozila, čije je učešće na američkom tržištu ipak bilo simbolično. Uprkos ekonomskom razvoju američke privrede, luksuzna vozila Daimler-Benz-a su imala učešće manje od 1\% na američkom tržištu. Smatrali su da mogu ostvariti korist od ekonomije obima u ovoj kapitalno intenzivnoj grani delatnosti. Sa godišnjim profitom od $\$ 2,8$ milijardi, visokom efikasnošću, niskim troškovima dizajna i razgranatom mrežom dilera činilo se da se Chrysler savršeno uklapa u njihove planove.

Transakcija je obelodanjena 7. maja, a preduzeta je 12. novembra. Septembra 1998. godine akcionari Daimler-a i Chrysler-a, kako većinski, tako i manjinski, velikom većinom su prihvatili merdžer kojim je stvoren DaimlerChrysler $A G(D C X)$. Novine i stručni časopisi su bili puni različitih izjava učesnika transakcije, kojima je ona prikazivana kao poslovna kombinacija koja će pomeriti granice automobilske industrije. Primera radi, izvršni direktor Daimler-Benz-a Jürgen Schrempp je pozdravio ujedinjenje kao „merdžer jednakih, merdžer rasta i merdžer nečuvene snage“ (Finkelstein, 2002: 3). The Wall Street Journal je nazvao transakciju „najvećim merdžerom u industriji svih vremena“. „Brak“ Daimler-a i Chrysler-a je trebalo da uzdrma globalnu automobilsku industriju i omogući njenu međunarodnu konsolidaciju (Vlasic, Bradley, 2010: 1). Konačno, The New York Times je uporedio merdžer Daimler-a i Chrysler-a sa venčanjem princa Čarlsa i ledi Dajane. U članku „Bračne scene“ (,Scenes from a Marriage“), Peter Schneider zaključuje ,... tradicionalna kompanija Daimler-Benz je zatražila ruku prelepe mlade The Chrysler Corporation, koja je prihvatila ponudu. Bio je to savršen spoj.“ (DaimlerChrysler Merger, 2010: 1).

Novoformirana kompanija sa 442.000 zaposlenih i tržišnom vrednošću od približno \$100 milijardi, trebalo je da realizuje identifikovanu i anticipiranu sinergiju u sledećim segmentima:

- svetski lider u saobraćaju; 
- uštede u troškovima istraživanja i razvoja i nabavci koje su posledica ekonomije obima;

- povećanje prihoda;

- kompletan asortiman proizvoda (Jeep i SUV automobili za Daimler-Benz, kao i luksuzna vozila za Chrysler);

- povećanje produktivnosti, kroz bolje iskorišćenje kapaciteta (DaimlerChrysler Post Merger Integration, 2010: 1).

Iako je pompezno najavljivana transakcija kao merdžer jednakih, već na startu njenog funkcionisanja bilo je očigledno da je Daimler-Benz većinski akcionar u novonastaloj korporaciji. Nemačka kompanija je kontrolisala većinu mesta u nadzornom odboru. Već u jesen 2000-te godine, u intervjuu nemačkom listu „Handelsblatt“, izvršni direktor DaimlerChrysler-a, Jürgen Schrempp, otkrio je svoje prave namere u vezi sa transakcijom između Daimler-Benz-a i Chrysler-a: „Merdžer jednakih je bio neophodan kako bi se dobila podrška zaposlenih u Chrysler-u i američke javnosti, ali on nikada nije bio objektivno moguć." (Finkelstein, 2002: 6).

Bez obzira na to što su očekivanja zaposlenih u obe kompanije bila takva da će transakcija omogućiti svakom entitetu da ostvari korist od jačine i sposobnosti drugog, performanse novoformirane korporacije nakon merdžera su bile potpuno drugačije, posebno $\mathrm{u}$ američkoj kompaniji. Nakon merdžera cene akcija američke kompanije su pale za polovinu, nakon početnog povećanja neposredno nakon realizovane transakcije.

Tokom perioda 1998-2000. godine model, Honda Odyssey postao je konkurent modelu Dodge Caravan, Toyotin model Toyota Tundra ,zapretio je“ modelu Dodge Ram, dok su terenska vozila General Motors-a, Ford-a, Nissan-a i Toyote postala pretnja delu tržišta koje je pokrivao Jeep. Chrysler je odgovorio na pretnje sitnim inovacijama i snižavanjem cene samo na početku 2001. godine. Tradicionalna dominacija Chrysler-a na tržištu terenskih vozila i lakih kamiona bila je ozbiljno narušena, a na pretnje nije odgovoreno na adekvatan način. Dok je menadžment Chrysler-a tavorio, tržište je nastavilo da funkcioniše uz znatno zaostajanje američke kompanije.

I pored stalnih nastojanja da se zaposleni i javnost ubede u to kako nema sukoba kulture u novom konglomeratu, razlike u kulturi između dve kompanije su u najvećoj meri odgovorne za neuspeh transakcije. Proizvodnja i menadžment nisu u potpunosti integrisane, zbog potpuno drugačijeg načina na koji se posluje u Nemačkoj i SAD: dok način poslovanja Daimler-Benz-a stavlja akcenat na više formalno strukturiran stil upravljanja, dotle je Chrysler favorizovao opušteniji i slobodniji stil (ovaj način upravljanja je u najvećoj meri zaslužan za finansijske uspehe američke kompanije pre transakcije). Takođe, obe kompanije su imale tradicionalno potpuno različite načine za rešavanje određenih problema, kao što su zarade i putni troškovi. Posledice ovih razlika su bile da je nemačka kompanija povećavala svoj uticaj, performanse i zadovoljstvo zaposlenih, dok je u američkoj kompaniji došlo do pogoršanja situacije. Dodatno nezadovoljstvo u nemačkoj kompaniji prouzrokovano je i lošim performansama američkog partnera koje je posledica napuštanja Chryslera od strane velikog broja ključnih rukovodilaca i inženjera. Nezadovoljstvo zaposlenih u Chrysler-u onemogućilo je nemačku kompaniju da preuzme celokupno poslovanje i nametne svoju kulturu u celoj kompaniji (Weber, Camerer, 2003: 401).

Tri godine kasnije tržišna vrednost DaimlerChrysler-a iznosila je $\$ 44$ milijarde i skoro je bila jednaka vrednosti Daimler-Benz-a pre transakcije. Njihove akcije su nestale sa $S \& P$ 500, a vrednost udela Chrysler Group-a opala je za trećinu u odnosu na vrednost pre transakcije. Nasuprot Mercedes-Benz-u i podružnici Smart Car, koja je ostvarila poslovni profit u trećem kvartalu 2001. godine u iznosu od 830 miliona evra, Chrysler Group-a je gubila novac zabrinjavajućim tempom. U istom tromesečju 2001. godine gubitak američke kompanije je iznosio \$512 milliona (Finkelstein, 2002: 3-4). 
Diskutabilno je da li se merdžerom ikada realizuje anticipirana i identifikovana sinergija, kao i da li se ikada uspešno integrišu kompanije uključene $u$ transakciju. Sve do 2002. godine DaimlerChrysler se pojavljuje kao dve nezavisne kompanije. U 2006. godini Chrysler je imao gubitak od \$1,5 milijarde, a 2007. godine obelodanio je plan o otpuštanju 13.000 zaposlenih, zatvaranju glavne fabrike za montažu i smanjenju proizvodnje u drugim fabrikama, u pokušaju da obnovi profitabilnost. Maja meseca 2007. godine DaimlerChrysler je obelodanio da želi da proda 80,1\% učešća u Chrysler-u privrednom društvu Cerberus Capital Management iz Njujorka, privatnoj firmi koja je specijalizovana za spašavanje problematičnih kompanija. Preostalih 19,9\% ostalo je u vlasništvu Daimler-a. Nemačka kompanija 27. 4. 2009. godine pristaje na prodaju preostalih 19,9\% udela u Chrysler $L L C$, pomenutoj firmi iz Njujorka i uplaćuje više od \$600 miliona u penzioni fond proizvođača automobila. Samo tri dana kasnije Chrysler LLC je, u skladu sa poglavljem 11, zatražio zaštitu od bankrotstva i najavio partnerstvo sa italijanskim proizvođačem automobila, kompanijom Fiat. Chrysler LLC je 1. 6. 2009. godine obelodanio prodaju nekih delova imovine i linija proizvodnje novoformiranoj kompaniji Chrysler Group LLC, dok je Fiat zadržao 20\% učešća u novoj kompaniji (Jarell, 2010: 1).

Dakle, kako je i zaključio već pomenuti autor Peter Schneider: ,... par je prošao izuzetnu transformaciju. Američka nevesta je nestala ili, da budemo precizniji, postala je ćelavi Nemac sa brkovima.“ (DaimlerChrysler Merger, 2010: 1).

$\mathrm{Na}$ kraju, o značaju i uticaju kulturnih različitosti na uspeh procesa akvizicije govore i sledeće konstatacije, koje su izneli Piero Morosini i Jürgen Schrempp. Morosini naglašava da je nerazumevanje razlika $\mathrm{u}$ nacionalnim kulturama isticano kao najznačajniji faktor visoke stope neuspeha prekograničnih zajedničkih ulaganja i strategijskih alijansi. On tvrdi da će transakcija neizbežno biti neuspešna ako se međukulturne razlike ignorišu tokom vrednovanja i pregovaranja o eventualnim poslovnim kombinacijama. Najzad, on zaključuje da je način na koji će kompanija nastala transakcijom upravljati međukulturnim izazovima $u$ direktnoj vezi sa njenim performansama nakon integrisanja i da može da bude faktor koji će odrediti da li će transakcija dugoročno biti (ne)uspešna (Niyati, 2008: 5).Može se reći da je sa izvesnim zakašnjenjem značaj kulturne integracije ili razvoja nove kulture shvatio i izvršni direktor DaimlerChrysler-a Jürgen Schrempp, koji ističe sledeće: „Potrebno je da prođe deset godina kako bi se integrisali načini razmišljanja ljudi.“ (Sudarsanam, 2003: 544).

Može se reći da se razlike u kulturi, odnosno razlike u pristupu izvršavanju poslovnih obaveza, na sličan način ispoljavaju i u našim uslovima. Naime, nakon procesa privatizacije u Republici Srbiji i otvaranja našeg tržišta za ulaganja stranih korporativnih privrednih društava (kupovina postojećih ili otvaranje novih privrednih društava), razlike u kulturi su često isticane kao problem koji onemogućava uspešno poslovanje takvih entiteta. Konstatacije da se ,radnici onesvešćuju za mašinama“ ili da „nisu u stanju da prihvate način izvršavanja radnih obaveza“" onako kako se to radi u privrednim društvima u razvijenim zemljama, samo su neki od faktora koji su često isticani kao smetnja potpunoj integraciji. Mada, poznajući naš mentalitet, možda su otpori naših radnika posledica činjenice da poslodavci, čiji kapital dolazi iz razvijenijih privreda, traže od njih zapadnoevropsku produktivnost, a zauzvrat nude srpske plate.

\section{ZAKLJUČAK}

S obzirom na to da razlike u kulturi utiču na svakodnevno poslovanje kompanija, one predstavljaju značajan faktor čijem rešavanju treba prići izuzetno pažljivo u procesima koji nastaju nakon realizovanog procesa prestrukturiranja korporativnih privrednih društava. S tim u vezi, preporučljivo je da se u postupku postakvizicione integracije: profiliše kultura kompanija uključenih u transakciju ili kompanija koje će nastati transakcijom, proceni usklađenost kultura $\mathrm{i}$ identifikuju područja potencijalnih konflikata koja se mogu prevazići određenim programima edukacije, seminarima i zajedničkim angažovanjem kompanija uključenih $u$ transakciju na njihovom prevazilaženju. 


\section{LITERATURA}

[1] DaimlerChrysler Merge. (2010). Preuzeto 23. 8. 2012, www.exampleessays.com.

[2] DaimlerChrysler Post Merger Integration. (2010). Preuzeto 23. 8. 2012, www.oppapers.com.

[3] Bruner, R. F. (2005). Deals from Hell: M\&A Lessons That Rise Above the Ashes. New York: John Wiley \& Sons, Inc.

[4] Đorđević, S. (2007). Poslovne kombinacije - računovodstveni aspekt. Priština: Ekonomski fakultet.

[5] Finkelstein, S. (2002). The DaimlerChrysler Merger. Hanover, New Hampshire, USA: Tuck School of Business at Dartmouth.

[6] Jarell, S. (2010). Capitalism and the Daimler-Chrysler Saga: Part 3 of 3, preuzeto 23. 8. 2012, http://learningfromdogs.com/2010/01/27/daimler-chrysler-merger3/.

[7] Meschi, P-X., Metais, E. (2008). The M\&A Paradox: The case of French Acquisitions in the United States. Working paper.

[8] Niyati, O. (2008). Failure Mergers, preuzeto 16. 6. 2012, http://jurisonline.in/?p=73.

[9] Shuler, A. J. (2010). Post Acquisition Integration - You Bought It, So Don't Break It: Five Best Practices in Post Acquisition Integration, preuzeto 14.6 . 2012, http://www.schulersolutions.com/post_acquisition_integration.html.

[10] Sudarsanam, P. S. (1995). The Essence of Mergers and Acquisitions, London: Prentice Hall

[11] Sudarsanam, P. S. (2003). Creating Value from Mergers and Acquisitions: The Challenges. London: Prentice Hall.

[12] United Nations Conference on Trade and Development (2000). World Investment Report 2000. New York; Geneva: United Nations.

[13] Vlasic, B., Bradley, A. S. (2010). Taken for a Ride: How Daimler-Benz Drove off with Chrysler, preuzeto 23. 6. 2012, www.paperbackswap.com.

[14] Weber, R. A., Camerer, C. F. (2003). Cultural Conflict and Merger Failure: An Experimental Approach. Management Science, Vol. 49.

Primljeno: 03.12.2012.

Odobreno: 15.12.2012. 